\title{
Record of Dicranosepsis javanica (de Meijere, 1904) (Diptera, Sepsidae) from Meghalaya (India), with morphological and genetic data
}

\author{
Lavinia IANCU ${ }^{1, *}$, Khlur MUKHIM ${ }^{2}$, Liviu MOSCALIUC ${ }^{3}$
}

\author{
${ }^{1}$ Institute of Biology Bucharest, 296 Splaiul Independenței, Bucharest 060031, Romania. \\ ${ }^{2} Z$ oology Department, Lady Keane, College, 793001, Shillong, Meghalaya, India. \\ 3"Grigore Antipa" National Museum of Natural History, 1, Sos. Kiseleff, Bucharest, 011341, Romania. \\ "corresponding author, e-mail: lavinia.iancu@ibiol.ro
}

Received: September 20, 2017; Accepted: November 13, 2017; Available online: December 29, 2017; Printed: December 31, 2017

\begin{abstract}
The present article reports Dicranosepsis javanica (de Meijere 1904) (Diptera: Sepsidae) from Meghalaya and makes a note of its Oriental distribution range. The specimens were sampled in January 2014 by sweep net in the village of Schnongrim, Jaintia Hills, Meghalaya, situated in the north-eastern part of India. A short morphological description is provided for the male specimen, while the female taxonomic characters are presented for the first time. The taxonomic identification of species was confirmed by DNA Barcoding.
\end{abstract}

Key words: Dicranosepsis javanica; Diptera; Sepsidae; Meghalaya; India.

\section{INTRODUCTION}

The species belonging to Sepsidae family are found worldwide, having a wide distribution range (Ozerov, 2005). The adults can be found on dung, flowers, decomposed organic matter, manure, excrements, rotting fruits, and other decaying substrates (Ozerov, 2005). Given this feeding preference, these species are also known as the black scavenger flies. Concerning their ecological importance, sepsids have a significant role in the decomposition of animal dung, especially cow dung.

From the Oriental region, 100 Sepsidae species are known to date (Ozerov \& Krivosheina, 2011), while in India this family comprises 45 species from 11 genera (Chakraborty et al., 2014). According to Ozerov (2003) and Iwasa \& Thinh (2008, 2012), the genus Dicranosepsis Duda 1926 comprise nearly 37 species, being very well represented in the Oriental region, by 29 species. Furthermore, according to Ozerov (2003), the females of this genus are difficult to be differentiated. However, it is known that the males and the females of the same species are often found in the same breeding environment (Pont \& Meier, 2002). Dicranosepsis javanica was first described by de Meijere in 1904, from Tosari (Indonesia). The species is also mentioned as being one of the widely distributed oriental species (Iwasa \& Thinh, 2012). To date, the diagnosis of the species was performed only for males, the female of the species remaining undescribed do to the so far apparent lack of morphological differentiation. Numerous authors (Duda, 1926; Steyskal, 1966; Munari, 1982; Iwasa, 1984, 1986; Iwasa \& Tewari, 1990; Iwasa \& Jayasekera, 1994; Ozerov, 1996; Iwasa, 1999; Ozerov, 2003, 2005; Iwasa \& Thinh, 2008, 2012; Ozerov \& Krivosheina, 2011) have dealt with the study of this oriental genus, providing taxonomic key to species, revised key, new records, taxonomic and faunistic notes. Regarding the species distribution in the Oriental region, records were cited from China (Guangdong, Taiwan), India, Indonesia 
(Java I.), Myanmar, Nepal, Pakistan, Philippines (Luzon), Sri Lanka, Thailand, and Vietnam (Iwasa, 1984; Xiao \& D. U. Yz, 2008; Letana, 2014).

\section{MATERIAL AND METHODS}

The specimens were sampled during an expedition in Shnongrim, Jaintia Hills, Meghalaya, India, in January 27, 2014. At the sampling time, an average temperature of $18^{\circ} \mathrm{C}$ and a relative humidity of $58 \%$ were recorded from the Meghalaya-Agricultural Meteorology Division (www.imdagrimet.gov.in/dwf/Meghalaya).

The sampling was performed by net sweeping several times in tall dry grass, in a human modified environment of clearings in secondary forest, few cattle and swine being present, at an altitude of $1159 \mathrm{~m}$, with the GPS coordinates lat. $25.350^{\circ}$ long. $92.516^{\circ}$ (Fig. 1).

Taxonomic identification and DNA barcoding

The specimens were sorted and preserved in $75 \%$ ethanol, according to Gullan \& Cranston (2010) recommendation. The male and female genitalia were photographed and drawn after being kept in lactic acid for several minutes. The taxonomic identification was performed under a stereomicroscope (Leica S6D), using Iwasa \& Thinh (2008) and Letana (2014) identification keys.

The taxonomic identification was supported alongside by DNA barcode. The genomic DNA was extracted by using the DNeasy Blood \& Tissue Kit and protocol (Qiagen) and its concentration was measured with a NanoDrop1000 (Thermo Scientific).

The PCR amplification of COI (Cytochrome c oxidase I) gene sequences was performed in a total volume of $50 \mu \mathrm{l}$, using a Mastercycler ProS System (Eppendorf). The pair of primers (10 pmols each) used in the reaction were: forward LCO1490: 5'-GGTCAACAAATCATAAAGATATTGG-3' and reverse HC02198: 5'-TAAACTTCAGGGTGACCAAAAAATCA-3' (Folmer et al., 1994). The PCR reaction was composed from $200 \mathrm{ng}$ insect genomic DNA, 1 unit of Taq DNA polymerase, $1 \mathrm{x}$ Taq buffer, $2.5 \mathrm{mM} \mathrm{MgCl}$, and $0.1 \mathrm{mM}$ dNTP (Thermo Scientific). The amplification initial incubation step was of $1 \mathrm{~min}$ at $94^{\circ} \mathrm{C}$, followed by 5 cycles

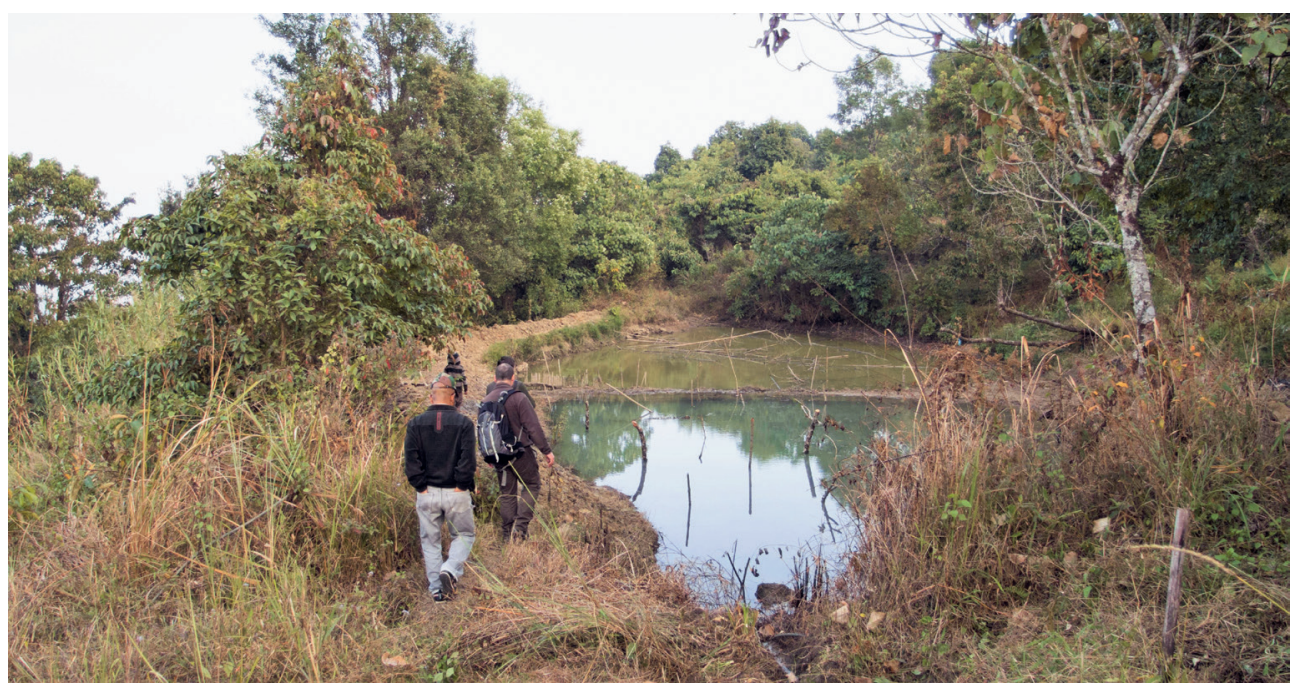

Fig. 1 - Habitat of the sampled specimens. 
of $30 \mathrm{sec}$ at $94^{\circ} \mathrm{C}$ (denaturation), $1.5 \mathrm{~min}$ at $45^{\circ} \mathrm{C}$ (annealing) and $1 \mathrm{~min}$ at $72^{\circ} \mathrm{C}$ (extension), followed by 35 cycles of $30 \mathrm{sec}$ at $94^{\circ} \mathrm{C}, 1.5 \mathrm{~min}$ at $51^{\circ} \mathrm{C}, 1 \mathrm{~min}$ at $72^{\circ} \mathrm{C}$ and a final extension step of $5 \mathrm{~min}$ at $72^{\circ} \mathrm{C}$.

The DNA COI gene fragments (710 bp) were analysed by electrophoresis on $1 \%$ agarose gels and sequenced (Macrogen). The specimens are preserved in the "Grigore Antipa" National Museum of Natural History scientific collection with the voucher id 155045.

Sequence analyses

For the species genetic identification, the nucleotide sequences were analysed and quality trimmed with BioEdit Software (Hall, 1999) and compared for similarity within nucleotide databases by using BLAST-NCBI (http://www.ncbi.nlm.nih.gov).

The resulted COI gene sequence of 655-bp (female) and 612-bp (male) of D. javanica (Diptera: Sepsidae), were deposited in the GenBank database and the accession numbers [KX360168] and [KY564172] were assigned.

Abbreviations

The terminology is the one used by McAlpine (1981), as follows: head (oc, occelar setae; $v t i$, inner vertical setae; vte, outer vertical setae); thorax ( $n p l$, notopleural setae; $d c$, dorsocentral setae; $s a$, supra alar setae; $p a$, postalar setae; $m$, mesopleural setae; ap sc, apical scutellar setae; $p p r n$, postpronotal setae); abdomen (katep, katepisternum; aneps, anepisternum; anepm, anepimeron; mer, meron); legs $(v$, ventral seta, $a v$, anteroventral seta); ovipositor (e, epiproct; $c$, cercus; $s$, sternite; $t$, tergite).

\section{RESULTS AND DISCUSSION}

According to the material available, the description and illustration of the morphological elements with taxonomic significance are presented below.

Dicranosepsis javanica (de Meijere, 1904)

Male description and genetic confirmation (Figs 2-4, 6 B, D)

The male of this species was described for the first time by Meijere, in 1904.

Body wholly black and shining, measuring approximately $4 \mathrm{~mm}$. (Fig. $2 \mathrm{~A}$ )

$\mathrm{Head}$. Round, with 10 peristomal setae disposed in the line, 1 oc, 1 vti, 1 vte, $p v t$ vestigial, and the genal lower part without long wavy hairs.

Wings. Hyaline, entirely irisated, with dark brown venation, and without dark spot near apex. R4+5 almost parallel with $\mathrm{M} 1+2$, no prominent posterior lobe on alula, upper and lower calypter whitish, margin of upper calypter with hairs, while the halters are whitish with the base darkened. (Fig. 2 B)

Thorax. Anepimeron with a shining area and the katepisternum shining anteroventrally. Scutellum and postscutellum slightly dusted, $1 \mathrm{pprn}, 2 \mathrm{npl}, 2 \mathrm{dc}, 1$ sa, 1 pa, 1 ap sc present. at the tip.

Abdomen. Sternite 3, 4, and 5 oblong shape. The epandrial process is bifurcated

Legs. Middle and hind femur without distinct setae. Fore femur with 3-4 spines at the middle part, without $a v$ setae in the basal part (Fig. 3 A-C). Hind tibia (Fig. 3 F) with a blackish trace of osmeterium anterodorsally. Mid tibia without brownish ring at the distal end; fore tibia (Fig.3 D-E). The tarsomeres of the fore legs are cylindrical and the fore coxa is straight.

Regarding the genetic confirmation, BLAST analysis of $D$. javanica male sequence revealed $96 \%$ coverage, $99 \%$ identity and a maximum and total score of 1074 compared with the reference sequence [EU435787].

Female description and genetic confirmation (Figs 5, 6 A, C, 7 A-B). 

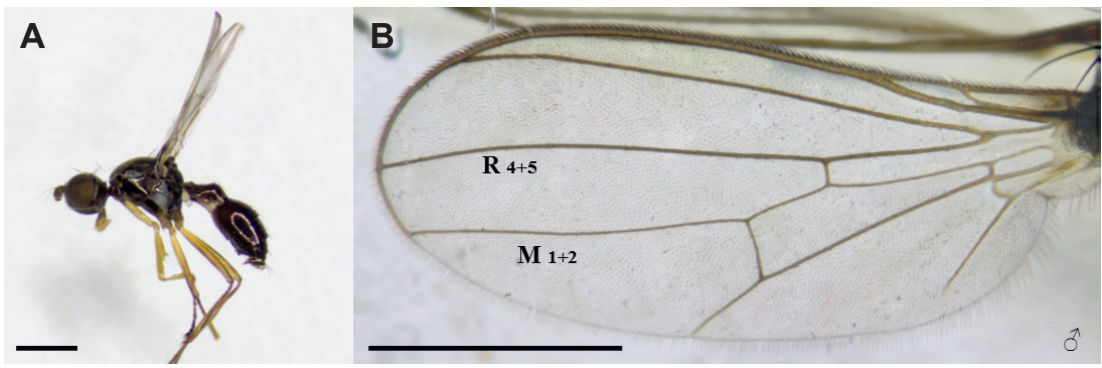

Fig. 2 - Stereomicroscopic images of Dicranosepsis javanica male. (A) habitus, lateral view; (B) wing venation. Scale bars: $1 \mathrm{~mm}$.

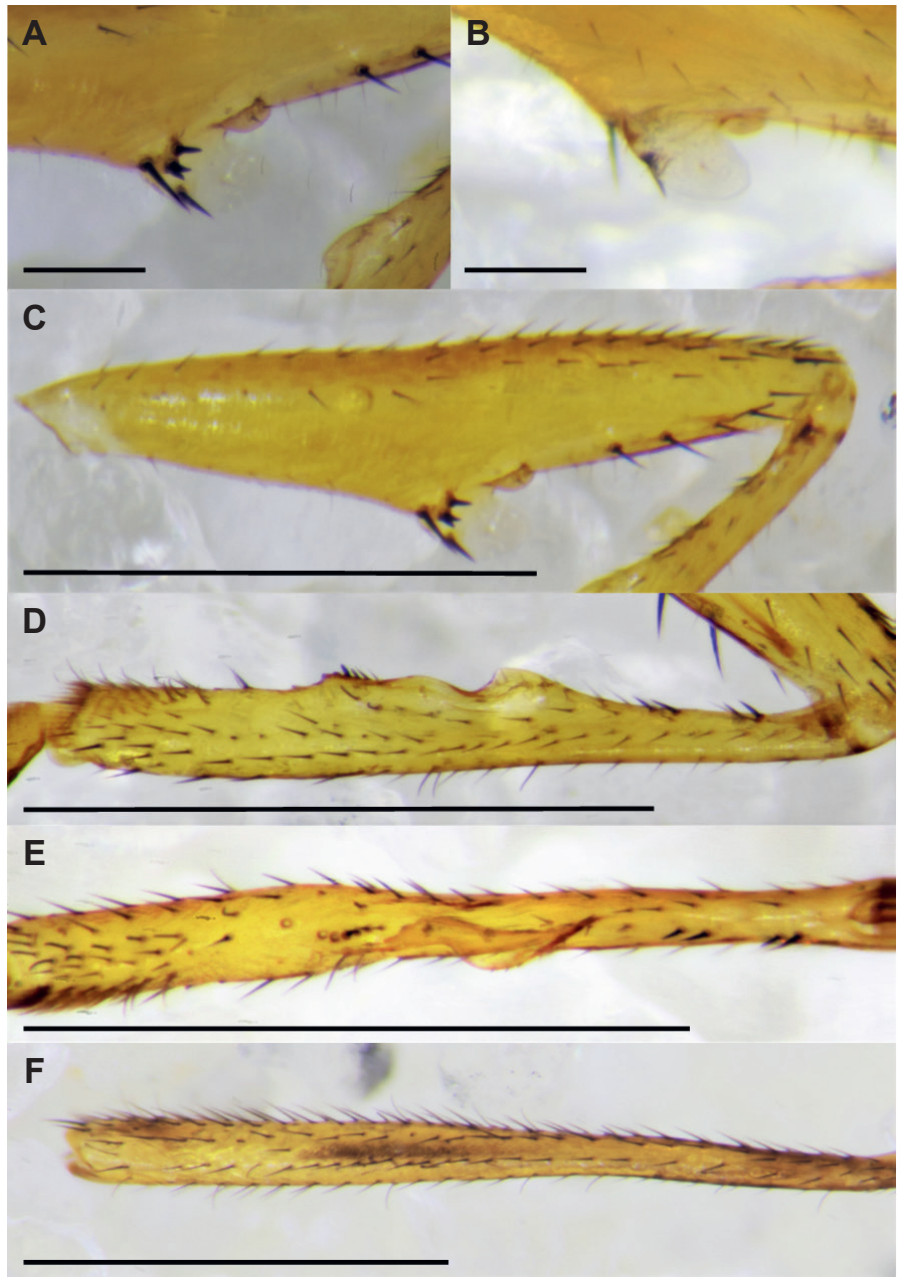

Fig.3 - Dicranosepsis javanica male legs. (A, C) fore femur anterior view; (B) fore femur posterior view, details; (D) fore tibia anterior view; (E) fore tibia posterior view; (F) hind tibia with osmeterium-like trace. Scales (mm): A-B - 0.1; C-F - 0.5. 
From the same sample, two female specimens were identified. The body length was of $2.9 \mathrm{~mm}$ (Fig. $5 \mathrm{~A}$ ), and the wing length measured between $2.0-2.2$ mm (Fig. 5 B).

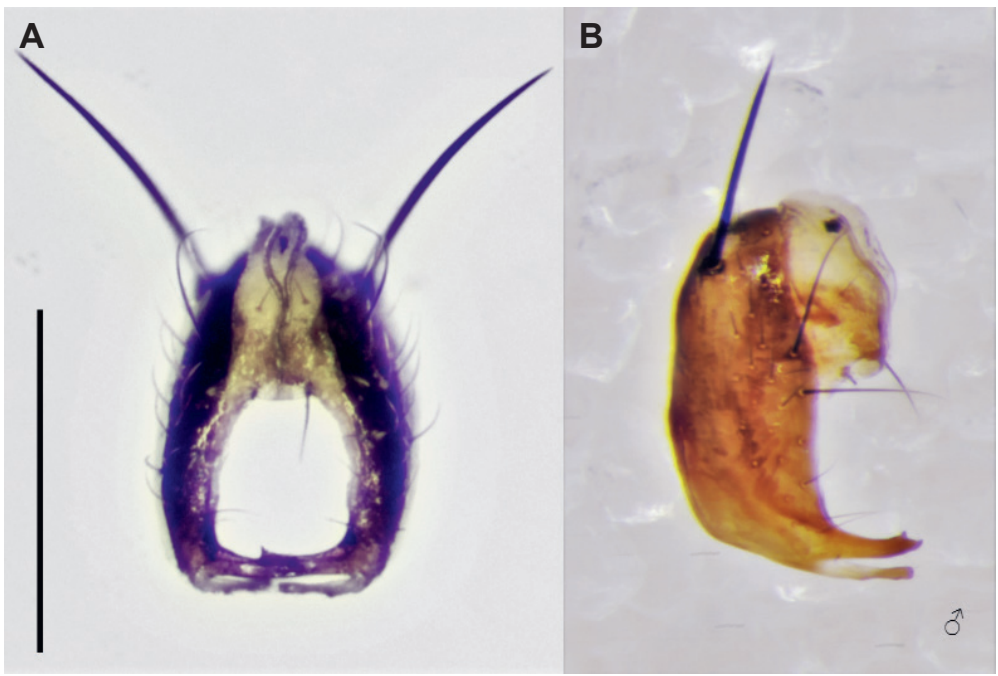

Fig. 4 -Dicranosepsis javanica male. Hypopygium. (A) posterior view; (B) lateral view. Scale (mm): 0.4.

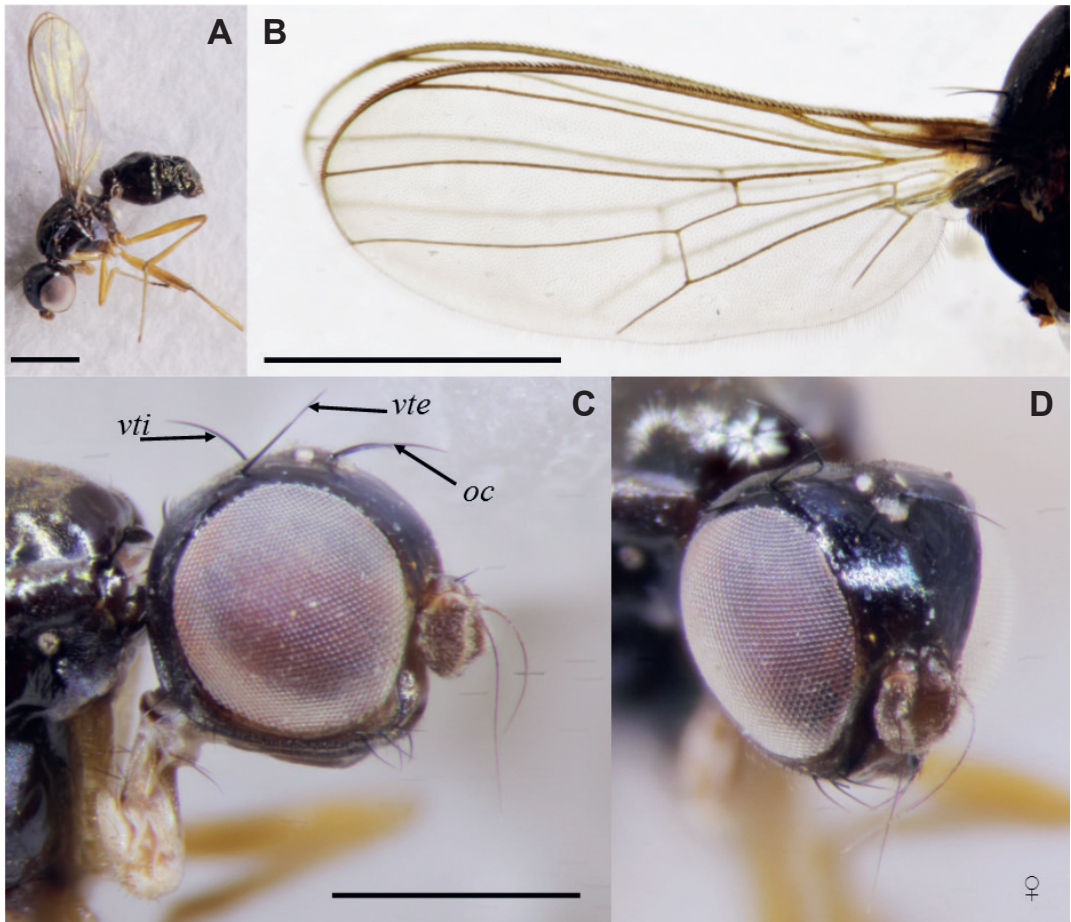

Fig. 5 - Stereomicroscopic images of Dicranosepsis javanica female. (A) habitus lateral view; (B) wing venation; (C) head, lateral view; (D) head, oblique view. Scales (mm): A-B - 1; C-D - 0.5. 


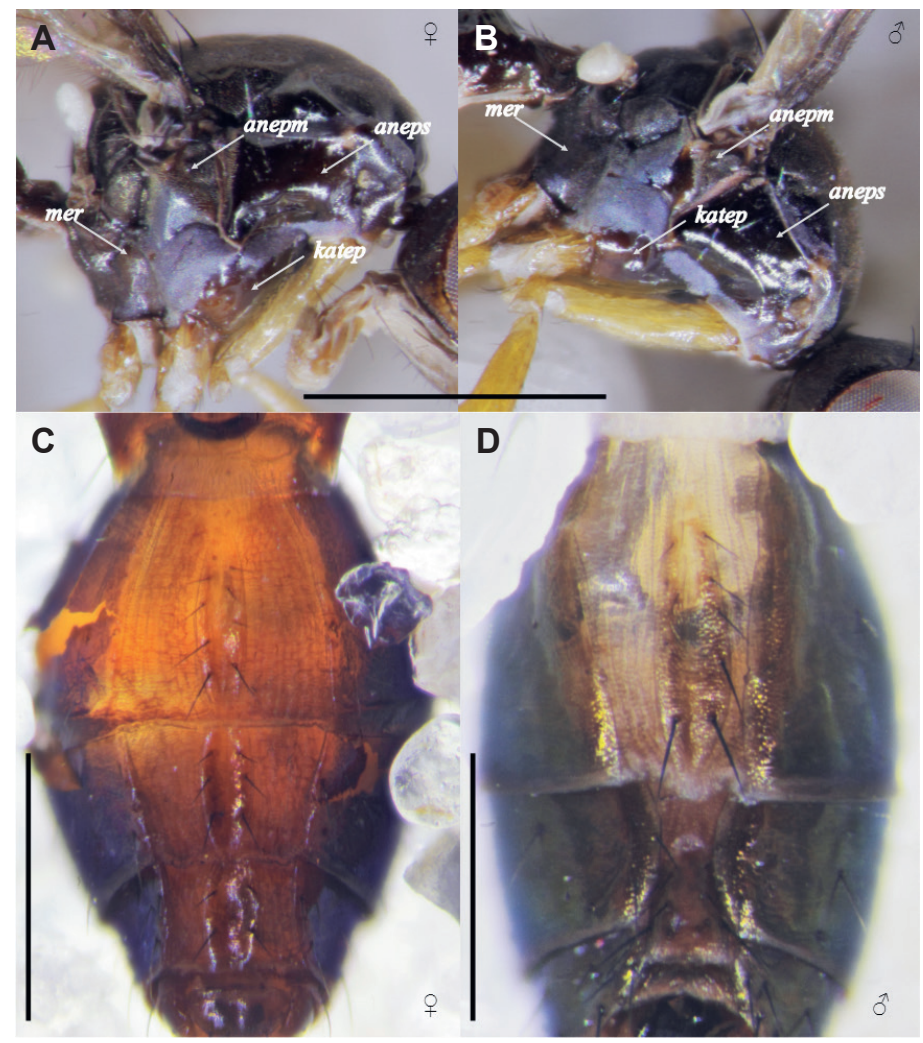

Fig. 6-Dicranosepsis javanica compared dusting, sternites and seate from ventral part of the abdomen. (A) female thorax, lateral view; (B) male thorax, lateral view; (C) female abdomen, ventral view; (D) male abdomen, ventral view. Scales $(\mathrm{mm})$ : A-B - 1; C-D - 0.5 .

Head. Round, with black, shining frons; face and gena brown-black, slightly dusted; facial orbits wider than in male; clypeus brownish; occiput black and dusted; antenna brown-black; arista black and bare; vibrissa with 3 setae; 12 peristomal bristles in a line disposed on the margin of gena, (Fig. $5 \mathrm{C}, \mathrm{D}$ ).

Thorax. Black and partially dusted, with mesonotum slightly dusted, without bristles; meron slightly dusted; anepisternum shining; anepimeron dusted and slightly shining centrally, while in male is shining in the anterior half part; katepisternum dusted posterodorsally and shining anteroventrally; anatergite, katatergite, metanotum, metanepisternum, and metepimeron dusted; scutellum and postscutellum slightly dusted 1 pprn, 2 npl, $1 d c, 1 s a, 1$ pa, 1 ap sc. Dusting pattern resembling male (Fig. 6 A, B).

Abdomen. With no distinct bristels, it is wholly black and shining; the 2nd tergite slightly narrowed anteriorly; sternite 3,4 , and 5 oblong shape as in male (Fig. 6 C, D): s3-4 pairs of bristles, s4-3 pairs of bristles, s5-2 pairs of bristles along the outer edge. Cercus small and cylindrical (Fig. 7 A). Epiproct present (Fig. 7 B). Hipoproct present, not sclerotized.

Legs. Yellow, with tarsomeres 3, 4, and 5 brownish; fore femur without distinct setae, but with small bristles; basitarsus of fore leg with one $v$ seta in the proximal 


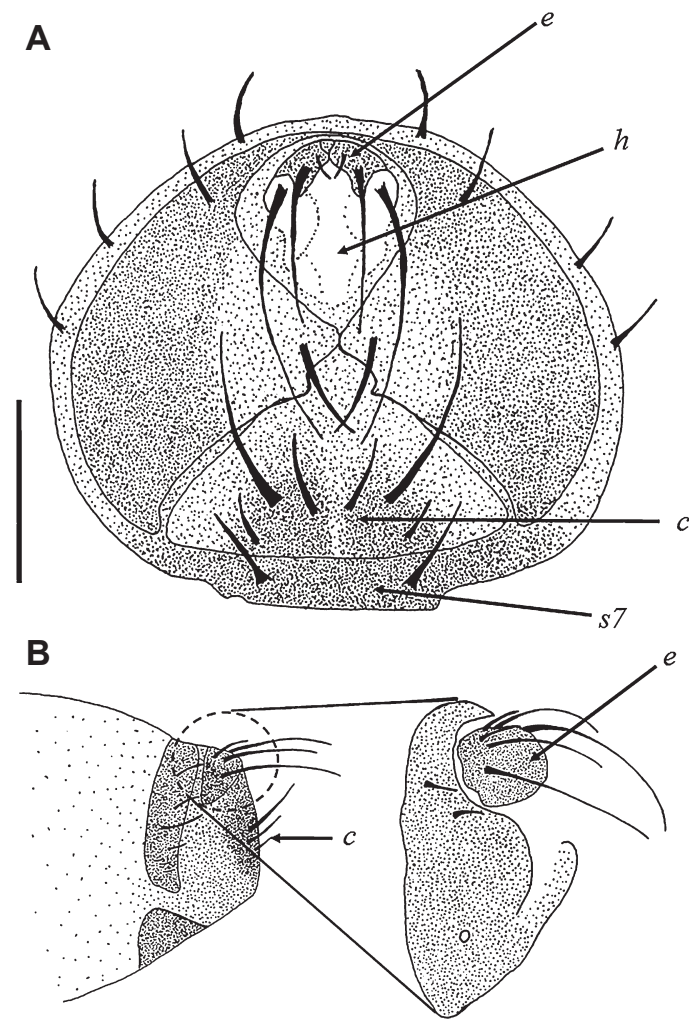

Fig. 7 - Female ovipositor drawing at camera lucida. (A) dorsal view (e-epiproct, h-hypoproct, ccercus, s-sternite); (B) lateral view. Scale (mm): 0.1.

first part; hind leg basitarsus with $2 a v$ setae; fore, middle and hind coxa yellow and brownish in the proximal part.

Both male and female specimens were confirmed by DNA barcoding. For the female specimen, the BLAST analysis of the nucleotide sequences presented $94 \%$ cover, $99 \%$ identity and a maximum and total score of 1103 with the COI gene fragment of $D$. javanica [EU435787] registered in the online database.

The present article aimed to provide supplementary data on $D$. javanica, by adding morphologic and genetic information from this south-eastern part of Asia, straightening the current knowledge regarding this oriental species. In the present case, the specimens were identified taxonomically and confirmed genetically by DNA barcode.

The Oriental distribution of $D$. javanica seems to be somehow fragmented, missing reports from Cambodia, Bangladesh, and Laos (Fig. 8). Given the species importance as decomposers, as well as their ability of expanding the distribution range, due to human activities and livestock relocation, signaling their presence in different geographical regions constitutes an important aspect. 


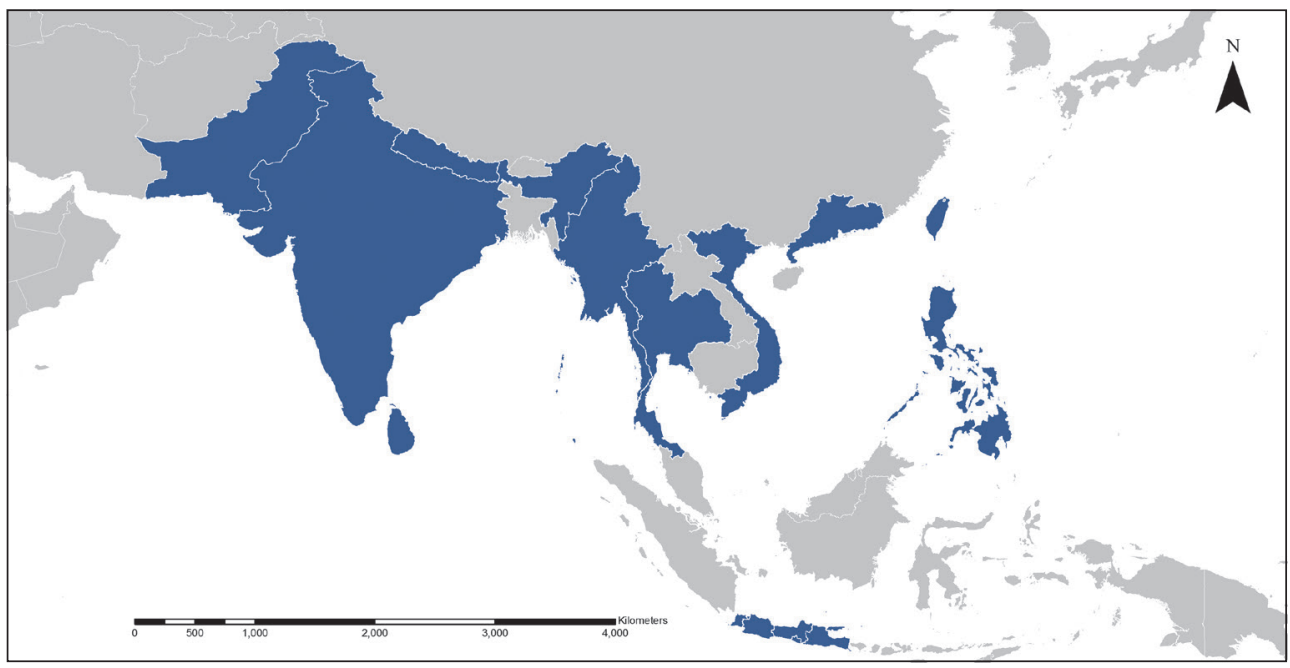

Fig. 8 - Dicranosepsis javanica, Oriental region distribution map.

\section{REFERENCES}

CHAKRABORTY, A., A. NASKAR, S. HAZRA, A. MAITY, D. BANERJEE (2014) Indian black scavenger flies (Insecta: Diptera: Sepsidae). Zoological Survey of India, New Alipore, Kolkata-700 053. doi:10.13140/RG.2.1.1771.4403

DUDA, O. (1926) Monographie der Sepsiden (Dipt.). Annalen des Naturhistorischen Museums in Wien 39(1925): 1-153 and 40(1926): 1-110.

FOLMER, O., M. BLACK, W. HOEH, R. LUTZ, R. VRIJENHOEK (1994) DNA primers for amplification of mitochondrial cytochrome c oxidase subunit I from diverse metazoan invertebrates. Molecular Marine Biology and Biotechnology, 3: 294-297.

GULLAN, P. J., P. S. CRANSTON (2010) The insects: An outline of entomology. Fourth edition, Wiley-Blackwell, 584 pp.

HALL, T. A. (1999) BioEdit: a user-friendly biological sequence alignment editor and analysis program for Windows 95/98/NT. Nucleic Acids Symposium Series, Vol. 41 (1999): 95-98.

IWASA, M. (1984) The Sepsidae from Nepal, with descriptions of eight new species (Diptera). Kontyû, Tokyo, 52(1): 72-93.

IWASA, M. (1986) Notes on the genus Toxopoda in the Oriental Region and Papua New Guinea with descriptions of two new species (Diptera, Sepsidae). Kontyû, Tokyo, 54(4): 654-660.

IWASA, M. (1999) The Sepsidae (Diptera) from Sulawesi, Indonesia, with descriptions of six new species. Entomological science, 2(1): 93-103.

IWASA, M., N. JAYASEKERA (1994) The Sepsidae from Sri Lanka, with description of a new species (Diptera). Japanese Journal of Sanitary Zoology, 45: 57-62.

IWASA, M., R. R. TEWARI (1990) Two new species of the genus Dicranosepsis Duda from India (Diptera, Sepsidae). Japanese Journal of Entomology, 58(4): 794-798.

IWASA, M., T. H. THINH (2008) Six new species of the genus Dicranosepsis Duda (Diptera, Sepsidae) from Vietnam, with a revised key to the species. Entomological science, 11: 65-73.

IWASA, M., T. H. THINH (2012) Taxonomic and faunistic studies of the Sepsidae (Diptera) from Vietnam, with descriptions of six new species. Entomological science, 15: 99-114.

LETANA, S. D. (2014) Taxonomy of black scavenger flies (Diptera: Sepsidae) from Luzon, Philippines. Philippine Science Letters, 7(1): 155-170.

MCALPINE, J. F. (1981) Morphology and terminology - adults. Pp 9-63. In: F. McAlpine, B.V. Peterson, G.E. Shewell, H.J. Teskey, J.R. Vockeroth, D.M. Wood (Eds) Manual of Nearctic Diptera. Agriculture Canada, Monograph, 641 pp.

MUNARI, L. (1982) Una nuova Dicranosepsis Duda della Sierra Leone (Diptera, Sepsidae). Ricerche Biologiche in Sierra Leone, Problemi Attuali di Scienza e di Cultura, Sezione: Missioni ed Esplorazioni VIII, Roma, Academia Nazionale dei Lincei 255: 47-51. 
OZEROV, A. L. (1996) A revision of the genus Dicranosepsis Duda, 1926 (Diptera, Sepsidae). Russian Entomological Journal, 5: 135-161.

OZEROV, A. L. (2003) Notes on flies of the genus Dicranosepsis Duda, 1926 (Diptera: Sepsidae). Russian Entomological Journal, 12(1): 87-92.

OZEROV, A. L. (2005) World catalogue of the family Sepsidae (Insecta: Diptera). Zoologicheskie issledovania (Zoological Studies), No. 8, 74 pp.

OZEROV, A. L., M. G. KRIVOSHEINA (2011) Two new species of Sepsidae from Vietnam. Russian Entomological Journal, 20(2): 211-214.

PONT, A. C., R. MEIER (2002) The Sepsidae (Diptera) of Europe (Fauna Entomologica Scandinavica). Brill, $198 \mathrm{pp}$.

STEYSKAL, G. C. (1966) Notes on flies captured in Treetops in Malaya (Diptera: Empididae, Neriidae, Platysto-matidae, Sepsidae, Muscidae). Proceedings of the U.S. National Museum, 120: 1-16.

XIAO, C. X., D. U. YZ (2008) Five new record species of Dicranosepsis Duda (Sepsidae) from China. Acta Zootaxonomica Sinica, 33(2): 420-422.

***http://www.imdagrimet.gov.in/dwf/Meghalaya

***http://www.ncbi.nlm.nih.gov 